\title{
EAl Endorsed Transactions

\section{The Role of the Electric Vehicle in Smart Homes: Assessment and Future Perspectives}

\author{
Vitor Monteiro $^{1, *}$, Jose A. Afonso ${ }^{2}$, Joao C. Ferreira ${ }^{3}$, Tiago J. C. Sousa ${ }^{4}$, and Joao L. Afonso ${ }^{5}$ \\ 1ALGORIMI Research Centre, University of Minho, Guimaraes, Portugal, vmonteiro@dei.uminho.pt \\ ${ }^{2}$ CMEMS-UMinho Center, University of Minho, Guimarães, Portugal, jose.afonso@dei.uminho.pt \\ ${ }^{3}$ Instituto Universitário de Lisboa (ISCTE-IUL), Lisboa, Portugal, joao.carlos.ferreira@iscte-iul.pt \\ ${ }^{4}$ ALGORIMI Research Centre, University of Minho, Guimaraes, Portugal, tsousa@dei.uminho.pt \\ ${ }^{5}$ ALGORIMI Research Centre, University of Minho, Guimaraes, Portugal, jla@dei.uminho.pt
}

\begin{abstract}
The wide spreading of electric mobility is imposing the application of new technologies of hardware and software for supporting new operation paradigms, not only in the perspective of improving smart grids, but also each time more in the perspective of boosting the preponderance of smart homes. Concretely, nowadays it is clear that the emergent technologies for smart homes, targeting power quality and a more efficient power management, are also altering the conventional electrical power grids toward smart grids. In this panorama, by relating the strategic pillars of electric mobility and smart homes, this paper has as main objective the characterization of the role of the electric vehicle (EV) in smart homes, presenting a broad assessment based on the state of the art, as well as creating a link with upcoming advanced operations. From the smart home point of view, since it should be equipped to deal with the requirements of the EV, the assessment of both on-board and off-board EV battery charging systems are considered along the paper. Furthermore, the presence of technologies such as energy storage systems, renewable energy sources and dc electrical appliances in smart homes towards sustainability is also reflected in this paper, but framed from the point of view of an off-board EV battery charging system, since it is more convenient for enabling the interface of these mentioned technologies. Looking the paper as a whole, a relevant contribution is the discussion of future operations for the EV in smart homes, also envisioning the opportunity for ac, dc, or hybrid power grids. Illustrative and strategic results are shown, covering all these features with specific details, not only based on numerical simulations, but also based on experimental results, which were obtained with a proof-of-concept laboratory prototype.
\end{abstract}

Keywords: Electric Vehicle, Smart Home, Smart Grid, Renewable Energy Source, Energy Storage Systems, Power Quality.

Received on 05 September 2020, accepted on 27 December 2020, published on 25 January 2021

Copyright $($ C 2021 Vitor Monteiro et al., licensed to EAI. This is an open access article distributed under the terms of the Creative Commons Attribution licence (http://creativecommons.org/licenses/by/3.0/), which permits unlimited use, distribution and reproduction in any medium so long as the original work is properly cited.

doi: 10.4108/eai.25-1-2021.168223

"Corresponding author. vmonteiro@dei.uminho.pt

\section{Introduction}

As is well predictable in numerous countries around the world, the growing paradigm of electric mobility is spreading in all the transportation sector, where miscellaneous technologies are evolving as a revolutionary contribution toward sustainability [1][2]. Inspecting in more detail the options that nowadays are accessible for the end-users, the utmost emblematic is the plug-in battery electric vehicle, which, in the context of this paper, with the objective of simplifying the analysis, is just referred as electric vehicle (EV). As confirmed, principally, along with the last two decades, a diverse number of commercially available EVs is increasingly appearing around the world for different purposes within the mobility sector, almost all of them equipped with an on-board EV battery charging 
system (EV-BCS), i.e., internal to the EV, and some of them are also prepared to be charged through an interface to an off-board EV-BCS [3][4][5][6], i.e., in this circumstance, the charger is situated externally to the EV. Nonetheless, from the point of view of the EV operation for the battery charging purpose, independently of the on-board or off-board charging technology for such purpose, only the possibility of charging with power directly from the grid is accessible, as can be found in [7] and [8]. This operation mode, which is common for both on-board and off-board EV-BCS, is titled as grid-to-vehicle $(\mathrm{G} 2 \mathrm{~V})$, since the power always flows from the power grid to the EV. For instance, this is also valid even when the EV charging process is implemented in public charging stations with interface of renewables, since, firstly, the power production from the renewables is injected into the power grid and then the EV is charged from the power grid (reducing the efficiency). On the other hand, when scrutinizing the EV charging from the perspective of the power grid, the circumstance is quite different, since the EV is understood not only as an additional and traditional load in the perspective of the power grid (independently of the power consumption for the charging and associated power quality aspects linked with such power consumption), but similarly to a traditional energy storage equipment for the power grid.

Aligned with this context and as a consequence, concentrating on the power grid perspective, the EV presence will be even more significant when controlled as a plugged-in flexible system, randomly introduced in the power grid, based on the user utilization, and skilled to offer three significant activities: (a) The EV is controlled by the on-board EV-BCS only for absorbing power from the power grid in the place where it is plugged-in, which can be performed with different power ratings depending on the user preferences, as well as the power grid management strategies for optimizing the load levelling scenarios for mitigating peak shaving occurrences; (b) The EV can be controlled for storing energy (i.e., according to the G2V mode) and transport it for different places in the power grid, knowing that the EV is a flexible load and randomly introduced (in this scenario, it is important to note that the primordial function of storing energy is for the EV circulation, however, when possible and conveniently agreed between all parties involved, the EV can be controlled in the perspective of exchanging power between two distinct electrical places, e.g., between a smart home and the power grid); (c) The EV can be controlled for injecting power into the power grid in the place where it is plugged-in, guaranteeing that the $\mathrm{EV}$ is not totally discharged since it needs stored energy for circulating (in this scenario, the EV operating power level is defined by the power management established by the smart grid and also according to benefit the user, e.g., receiving money/discount incentives for the next charging operation, and always guaranteeing high levels of power quality for all operating power levels).

Supported by the aforementioned context of a cooperative interaction among the power grid and the EV-BCS, it is recognized that besides the $\mathrm{EV}$ operation in $\mathrm{G} 2 \mathrm{~V}$ mode, and aligned with advanced technologies in smart grids, there is the inevitability of allowing an innovative operation for the EV-BCS that consists in the power flow in opposition to the G2V mode, i.e., in this innovative case, the power is provided by EV and delivered to the power grid, which is an operation mode well identified in the literature and denominated as vehicle-to-grid (V2G) [9][10][11]. In such circumstances, the mentioned miscellaneous occasions of collaboration among the power grid management system and the EV user, through appealing to the G2V/V2G modes, are leading and emergent topics for the industrial sector, as well as for innovative investigations, as confirmed in [12], [13], and [14]. Furthermore, as previously mentioned, it is necessary to reinforce that the V2G mode is a technology that involves bidirectional EV-BCS, both in terms of power operation and communication with the power grid, which is being recognized and introduced as a new reality for the transportation sector. In fact, progressively, researchers and some manufacturers of the automotive sector are introducing hardware (e.g., EV-BCS with bidirectional communication and power capabilities) and software (e.g., communication networks, as the survey presented in [15]) technologies with the objective to support the massive introduction of on-board EV-BCSs prepared to deal with G2V/V2G operation modes in coordination and cooperation with the smart grids, which are more and more a reality with the possibility of integrating innovative technologies with those referring to $\mathrm{EV}$.

With the objective of introducing an illustrative case example, Figure 1 shows the incorporation of an on-board EV-BCS contextualized within a smart home, where it is possible to recognise the detail of the power interaction, bidirectional, as expected, of the G2V/V2G modes with the smart home. The situation reported on this figure is a conventional interface guaranteed by the G2V/V2G modes, as traditionally occurs with all EVs in smart homes, where it is evidenced that the on-board EV-BCS can be controlled for the G2V/V2G modes (individually, according to the requests and necessities of the involved parts) by the smart home power management. As exemplified, from the EV point of view, it can consume power from the grid (during the $\mathrm{G} 2 \mathrm{~V}$ mode), or it can be controlled for delivering power to the smart home (during the $\mathrm{V} 2 \mathrm{G}$ mode) or to the smart grid, or even both (i.e., it can be convenient to deliver power for the smart home and a little part also for the smart grid). However, it is expected that the V2G mode will only be used during specific moments, ensuring that only part of the energy stored in the EV batteries is used for this purpose.

Additionally to the flexible controllability offered by the EV-BCS for smart homes and smart grids when operating in G2V/V2G modes, more recently, pioneering operation modes, involving the EV and the smart grid, are emerging from the point of view of power quality. Some of these examples are correlated to the option to consider the EV as an independent power source when occurring power outages (i.e., the EV can operate as the main voltage source during few moments according to the battery state-of-charge and the user permission, e.g., during the integration in the smart home or even in scenarios of islanded grids). Additionally, 
other example, even more futuristic but realistic, considering the structure of the EV-BCS regarding power electronics, is related to the possibility to consider the EV as a shunt active power filter. Consequently, dynamically, the EV-BCS can contribute to compensating current harmonics and, simultaneously (or not), reactive power for the electrical installation (e.g., a smart home where it is plugged-in and locally controlled based on the current consumption of the electrical appliances, or otherwise a smart grid with wider scope) [16].

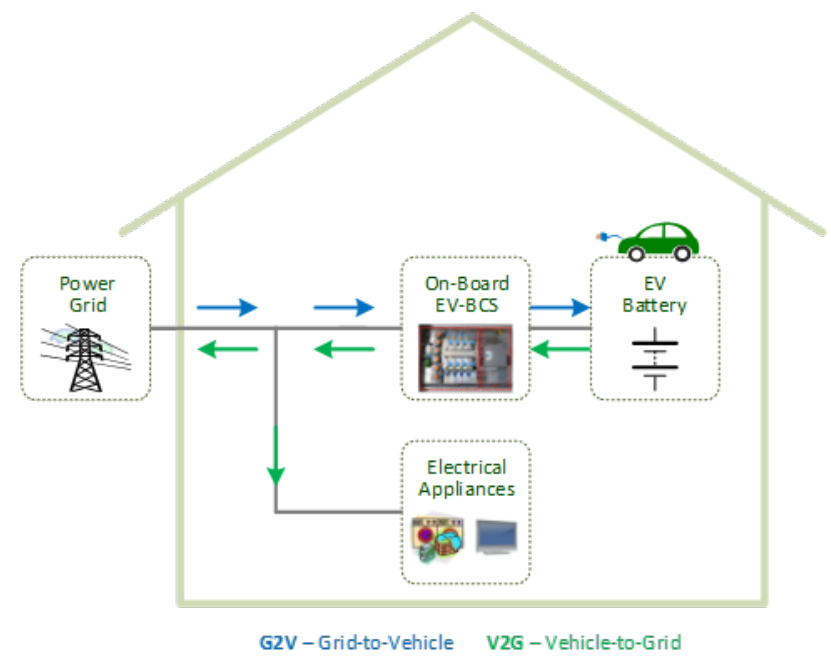

Figure 1. Smart home with an on-board EV-BCS covering the $\mathrm{G} 2 \mathrm{~V}$ and $\mathrm{V} 2 \mathrm{G}$ modes.

Knowing the significance of the above-mentioned collaborations among the EV and the smart home or smart grid, and creating future perspectives, it can be emphasized as leading contributions of this paper: (a) A more meticulous and broad assessment about the state of the art operation modes and technologies about the EV interaction in smart homes and smart grids; (b) A comprehensive explanation about future perspectives of operation paradigms associated with the EV and technologies as renewables and external energy storage systems, all of them framed with smart homes; (c) A validation based on numerical simulations and experimental results obtained with a developed proof-of-concept laboratory prototype. The contributions and content of this paper should be seen as an extended version of an original paper by the same authors, which is introduced in [17], where as additional new contributions can be highlighted: (a) A more accurate explanation of the operation modes offered in the original version, supported by supplementary new and recent references, as well as advanced modes for the EV-BCS operation; (b) The presentation of the laboratory prototype used to obtain illustrative and key experimental results and its brief description in terms of power electronics (both power system and control system), as well as additional experimental results.

The rest of this extended paper is organized as follows. After the introduction, section 2 presents an overview of operation modes and technologies associated with the EV introduction in smart homes and also in the perspective of smart grids, section 3 introduces the future perspectives of operation modes, highlighting the interaction of the EV with technologies as renewables and energy storage systems, as well as ac, dc or hybrid electrical installations in smart homes, section 4 presents the key results, both computational and experimental, and, finally, section 5 finalizes the paper with the main conclusions.

\section{EV in smart homes and smart grids: overview of operation modes}

In the introductory section, it was mainly considered and described the possibility of the EV interface work in bidirectional power operation according to the G2V/V2G modes, both in the perspective of the smart home and smart grid (i.e., depending on the requirements). As mentioned, nowadays, such G2V/V2G modes are a reality for numerous purposes; nonetheless, these modes are only valid when the objective is the exchange of active power between the EV and the power grid, aiming smart grids in a viewpoint of an on/off control, without ignoring the power grid limitations. As investigated and demonstrated in several published studies, as in [17], [18], [19], [19], [20], [21], [22], and [23], this option of bidirectional power interface has an extremely vital impact, permitting, for example, to control the EV to overcome issues of efficiency and power quality in the power grid. In this standpoint, with the consent of the EV driver (e.g., guaranteeing advantageous tariffs for programs of power management sustained by the G2V/V2G modes, and knowing that the EV battery can be degraded when subjected to additional charge/discharge cycles), the EV can be controlled by an algorithm of power management of the smart home or smart grid, which outlines the programming modes for charging $(\mathrm{G} 2 \mathrm{~V})$ and discharging (V2G) processes [24].

As a consequence of the flexibility of the EV to be randomly plugged-in in diverse places of the power grid, it contributes for a more exigent control strategy, where the controllability presented by the smart grid assumes a relevant complexity. Further, as investigated in [25] and in [24], the flexibility presented by the EV for operating in different modes, offering innovative functionalities, is essential also for scenarios of microgrids. In [25] and [28] experimental considerations for the EV operation in G2V/V2G scenarios are presented and validated, and, in a future perspective of interactions between the EV and smart grids, advanced G2V/V2G interfaces are presented in [29]. An online scheduling for hierarchical $V 2 G$ is offered in [30], presenting the design, the formulation, and the control algorithm. The existing flexibility offered by the G2V/V2G modes is even more appropriate when analysing from the perspective of cooperating with the power grid to compensate the intermittent power production from renewable energy sources (RES), obviously, mainly through the G2V mode (e.g., where the EV charging power level can be adjusted in function of the RES power production) [31]. By analysing the EV operation in this cooperative scenario of operation, from the point of view of the smart grid (or 
smart home), it can be recognized as an energy buffer for the power grid, capable of consuming, storing, or delivering power as a function of the RES intermittence in the power production.

A contextualization for accepting the EV operation in G2V mode directly aiming the RES power production, and as a influence for extenuating greenhouse gases emissions, is available in [32]. Additionally, other view linking also the EV operation and the RES production, with the final aim of reducing costs of operation and reduce greenhouse gases emissions, is investigated in [33], and the description of G2V/V2G modes directly influenced by the RES power production for a demand-side management is accessible in [32]. Associating the assorted EV operation modes with the RES intermittence in the power production rises innovative perspectives, not only contextualized with smart grids, but also with smart homes, since, as verified in [32], smart homes have an important boost consequence for the future improvement and modernization of smart grids. Consequently, in this situation, technologies and foresights for adapting the EV G2V/V2G operation in smart homes are introduced and deliberated in [33], whereas an enhanced EV collaboration is conferred in [34] from the client viewpoint. The technologies presented and discussed aforesaid are mainly related to the involvement of on-board EV-BCS operating in G2V/V2G modes and contextualized with smart homes. Nonetheless, additional potentials of operation continue emerging as feasible commitments for the EV in smart homes but attempting smart grids.

When the EV is plugged-in at home, a special mode that can be considered is the home-to-vehicle $(\mathrm{H} 2 \mathrm{~V})$, which is similar to the $\mathrm{G} 2 \mathrm{~V}$, since the power also flows from the power grid to the EV. However, it is more advantageous than the traditional on/off $\mathrm{G} 2 \mathrm{~V}$ mode, where the distinguishing feature relies on the controllability. Based on this mode, the EV operates with a dynamic power, varying between zero and the maximum power allowed (i.e., it can allow any value within the range of operating power).

In the $\mathrm{H} 2 \mathrm{~V}$ mode, when compared to the controlled G2V mode, the on-board EV-BCS can likewise be remotely power-managed according to the set points taken by the algorithm of power management. This mode is especially suitable for a smart home power management in unification with controlled electrical appliances (i.e., capable to be on/off controlled without neglecting the user comfort). In these circumstances, the management algorithm can authorize different levels of priority for the EV, as well as for the electrical appliances, following the user preferences (e.g., defined by a mobile app).

From the EV point of view, three main conditions can be distinguished: (a) The EV is limited to have highest priority; consequently, it is charged with maximum power, while the electrical appliances can be turned-off to prevent the circuit breaker trip. This condition matches to a severe case when it is necessary to charge the EV as fast as possible (with the operating power limited by the EV-BCS or by the circuit breaker of the electrical installation), and the operation of the additional electrical appliances is not important. (b) The $\mathrm{EV}$ is limited to have priority over some specific electrical appliances (previously defined by the user and that can be changed whenever necessary); therefore, with the objective of avoiding the circuit breaker tripping, a value of charging power lower than the nominal power of the EV-BCS is defined, and the turn-on and turn-off of the electrical appliances is constrained. As consequence, the EV charging is performed by a secure power and the electrical appliances are controlled. (c) The EV is managed to diminish its operation to a minimum, through defining a minimum priority for its operation within the smart home; subsequently, the EV-BCS power operation obeys to a maximum value (which matches the maximum value of the circuit breaker and its nominal power) and the power consumption in the smart home due to the presence of the turned-on electrical appliances. Successively, in this case, the instantaneous operating power of the EV-BCS is directly adjusted by the power consumption of the electrical appliances.

\section{EV in smart homes and smart grids: future perspectives of operation}

In this section, future perspectives for the EV in smart homes are exhibited. Accordingly, additionally to the operation paradigms outlined in the preceding section (i.e., the $\mathrm{G} 2 \mathrm{~V} / \mathrm{V} 2 \mathrm{G}$ and $\mathrm{H} 2 \mathrm{~V}$ modes), novel challenges in terms of infrastructures are shown, including the demands of smart homes.

In Figure 2 is displayed a concept of an on-board EV-BCS in smart homes, considering the abovementioned operation modes and a new one, which is correlated with power quality aspects. As it can be observed, these operation modes are important and remarkably beneficial for the smart home, also contributing for new energy policies for smart grids. As an illustrative example, when operating in bidirectional mode, three distinct cases can be considered for the on-board EV-BCS: (a) Exchange power with the smart home, where the EV can give power according to the specifications of the home management system; (b) Exchange power with the smart grid, where the EV can give power according to the specifications of the smart grid; (c) Exchange power, at the same time, with the smart home and with the smart grid. This representative example is straight linked with the G2V/V2G modes, nevertheless, a comparable situation is for the vehicle-for-grid (V4G) mode, where the on-board EV-BCS can be controlled to neutralize power quality problems, both in the smart home and in the smart grid perspectives.

An enhanced V4G mode for on-board EV-BCS operating in smart grids is proposed in [38], supported by a complete and extensive experimental validation. It is necessary to remark that, in this case, the on-board EV-BCS can neutralize about all the current harmonics and the power factor of the smart home, however, in the smart grid panorama, it simply provides the operation to mitigate a portion of the before-mentioned power quality problems. In this situation, a different panorama for the smart grid appears, which is associated with the selective harmonic 
current compensation (i.e., a situation where each EV can be controlled to provide a distinct harmonic current) and controlled reactive power (i.e., a situation where each EV is capable to produce a small amount of reactive power to compensate a specific value of power factor in the smart grid). Notwithstanding the obvious gains of these operation modes for the smart home and the smart grid, an important limitation is recognized: these operation modes are only possible when the on-board EV-BCS is accessible, i.e., when the EV is stationed at the smart home. On the opposite hand, if examined from the power grid point of view, in terms of shifting power and in terms of controllability, a further fundamental benefit is distinguished: these operation modes are accessible in the location where the EV is placed, i.e., the EV is a dynamic system in the smart grid, able to operate in unconventional modes according to the constraints.

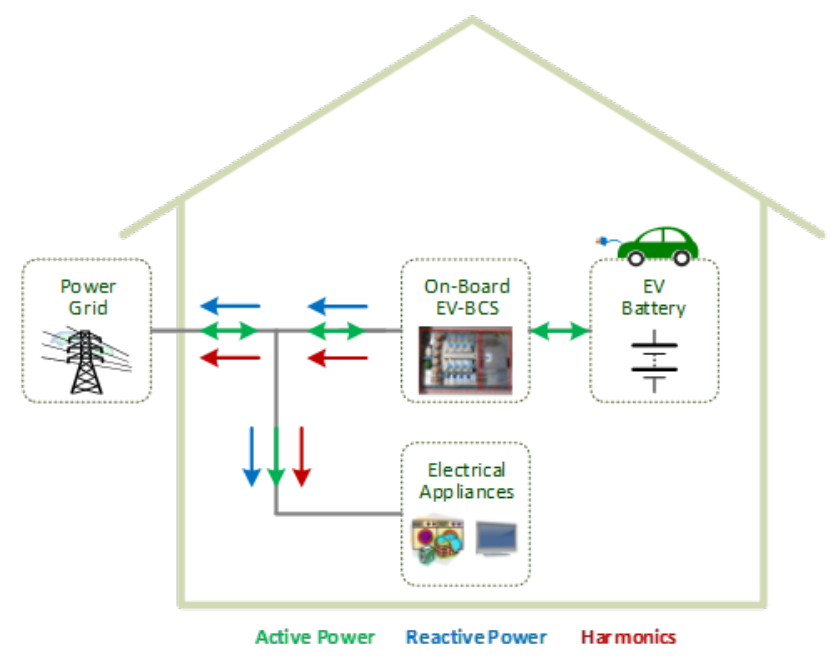

Figure 2. Smart home with an on-board EV-BCS covering the G2V and $V 2 G$ modes, as well as compensating power quality problems.

Besides the advantage of mitigating power quality problems associated with harmonic currents and reactive power, the on-board EV-BCS can also be controlled during power outages. In this circumstance, as illustrated in Figure 3, the on-board EV-BCS provides power for the smart home, but the current waveform is defined by the electrical appliances (i.e., the on-board EV-BCS can operate with a non-sinusoidal current and low power factor). In this example, the energy source is the EV battery, consequently, it should be managed with the permission and benefit of the EV user. For example, in this mode, the on-board EV-BCS system can be used only to give power for priority electrical appliances in the smart home (to be determined and reconfigurable by the user). Furthermore, this mode is more useful for short periods.

Concerning off-board EV-BCSs, the abovementioned operation modes can also be applied. In Figure 4 is displayed a concept of an off-board EV-BCS in smart homes when the EV is placed at home. Using an off-board EV-BCS, the extended opportunities are even more important, since the equipment is continuously placed at the smart home. Consequently, remarkable operation modes are possible separately of the EV being placed. For example, the off-board EV-BCS can give power quality services, precisely as the on-board EV-BCS, for both the smart home and for the smart grid, but such services can be given separately of the EV presence. On the opposite hand, G2V/V2G modes are only accessible, as for on-board EV-BCS, when the EV is parked (with the batteries used as the energy source).

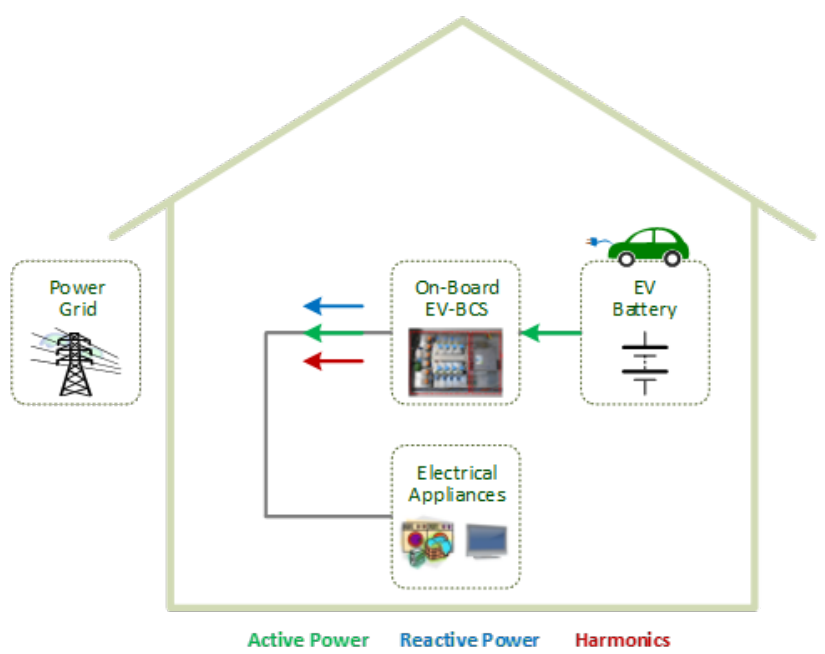

Figure 3. Smart home with an on-board EV-BCS used as power supply, where the EV batteries are the energy source.

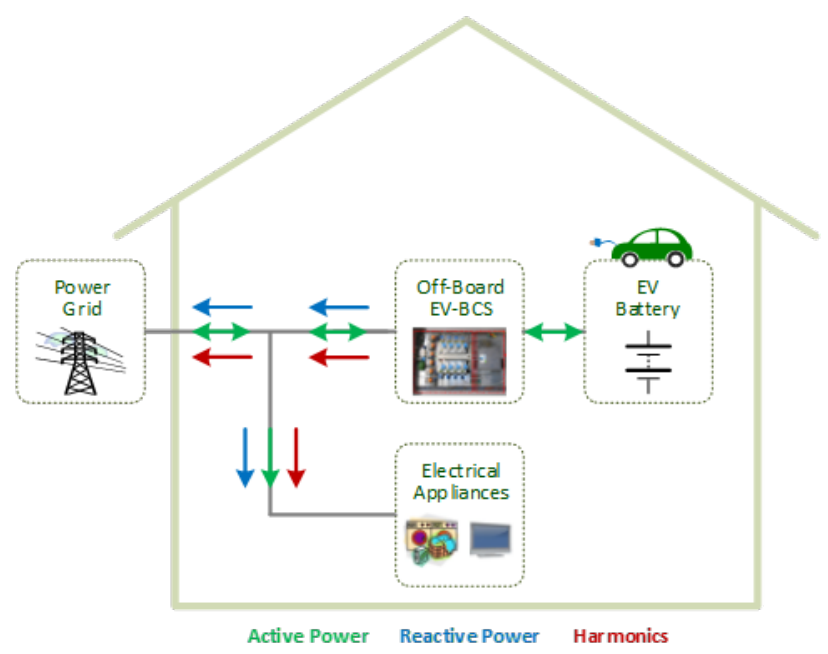

Figure 4. Smart home with an off-board EV-BCS covering the G2V and $\mathrm{V} 2 \mathrm{G}$ modes, as well as compensating power quality problems.

In Figure 5 is shown a concept of an off-board EV-BCS in smart homes when the EV is not placed at home. As depicted, the corresponding operation modes are accessible (i.e., G2V/V2G and compensation of harmonic currents and power factor), excluding the opportunity of managing the $\mathrm{EV}$ as power supply, i.e., when occurring power outages. Nonetheless, the principal expected perspectives are associated with the off-board EV-BCS operation and, more specifically, including the chance of interfacing additional technologies for smart homes as RES or energy storage systems (ESS). Therefore, the future perspectives are based on the feasibility of using the same off-board EV-BCS to 
interface, through a shared dc link, a unidirectional dc-dc converter for RES and a bidirectional dc-dc converter for an auxiliary ESS [38]. It is necessary to remark that the combination of an EV off-board battery charging system with this opportunity is a perfect answer to embrace in the smart home: electric mobility; RES; ESS [39][39][40]. This circumstance is illustrated in Figure 6 , where the single interface with the power grid is a suitable important characteristic [41][42].

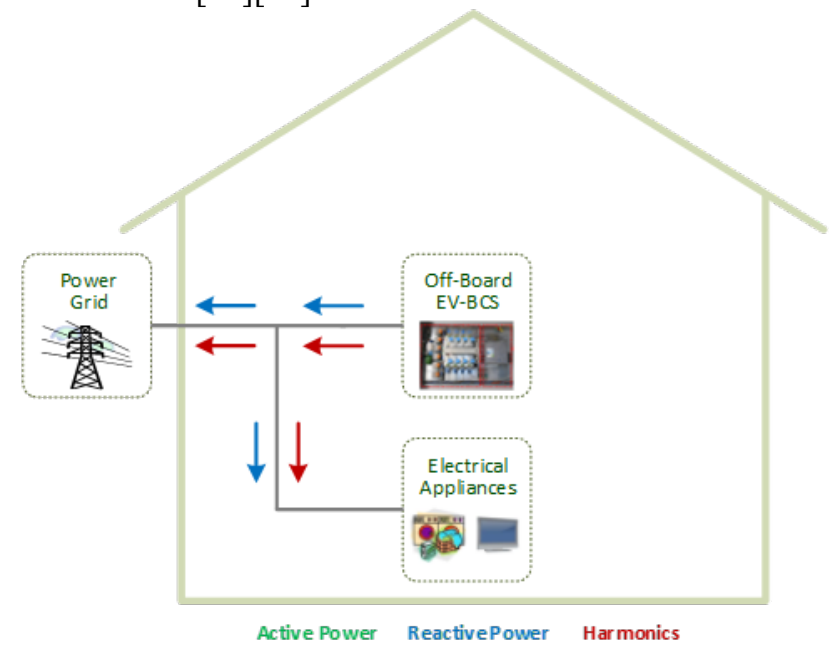

Figure 5. Smart home with an off-board EV-BCS compensating power quality problems without a parked EV.

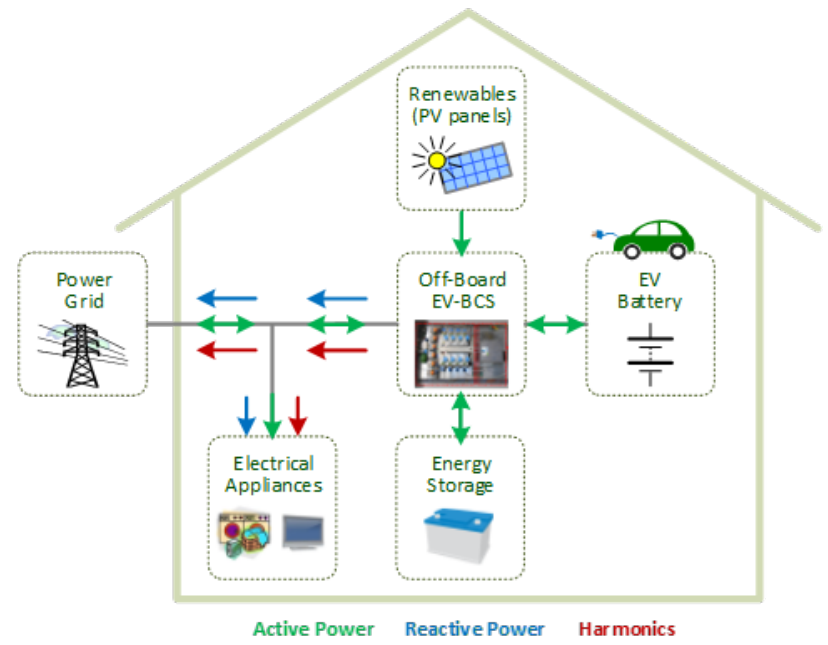

Figure 6. Hybrid ac and dc smart home with an off-board EV-BCS, interfacing a RES and an ESS through the dc grid established by the off-board EV-BCS. The electrical appliances are directly linked to the ac power grid.

Furthermore, if including the migration from ac grids to $\mathrm{dc}$ grids, this is even more appropriate, because the obligations of power converters are drastically diminished (it is crucial to take into account that the preponderance of the electrical appliances at home level is formed by a front-end ac-dc converter applied solely to connect to the ac grid). Consequently, a whole future perspective of combining an off-board EV-BCS in a smart home, principally concentrating in an internal dc grid, is illustrated in Figure 7.

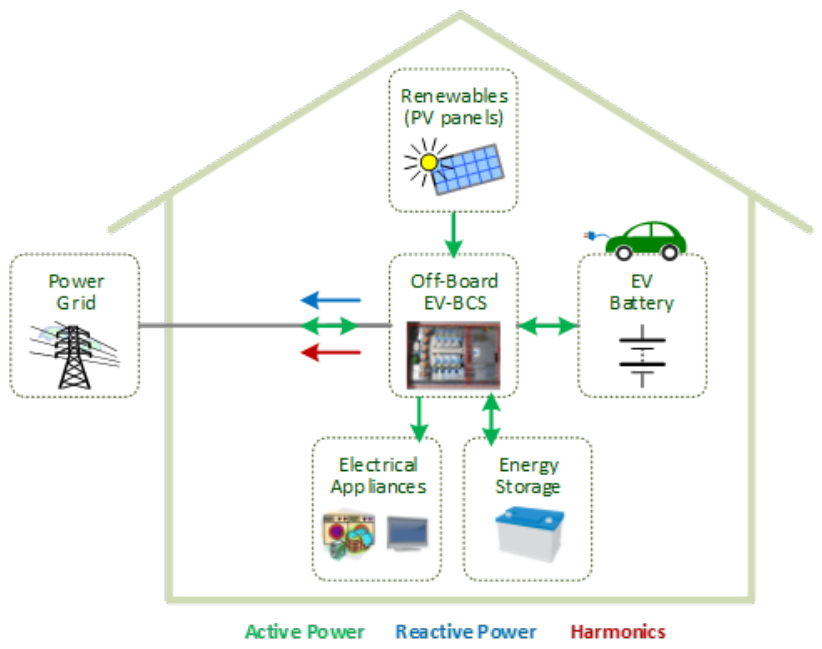

Figure 7. Dc smart home with an off-board EV-BCS, interfacing a RES and an ESS through the dc grid established by the off-board EV-BCS. The electrical appliances are directly linked to the dc grid established by the off-board EV-BCS.

\section{Computational and experimental validation}

Under this section, a matching among three foremost states was analysed, as demonstrated in Figure 8: (a) A typical ac smart home with self-governing power converters for each technology (on-board EV-BCS, RES, ESS, dc electrical appliances, and ac electrical appliances); (b) A hybrid ac/dc smart home including an integrated off-board EV-BCS for a RES and for an ESS, sharing a common dc link; (c) A dc smart home with an integrated off-board EV-BCS, based on a single interface with the grid and with dc-dc or dc-ac converters for interfacing each technology (on-board EV-BCS, RES, ESS, dc electrical appliances, and ac electrical appliances).

These three states were validated using computer simulations with a complete model developed with the PSIM software, where: (a) as RES, a set of photovoltaic (PV) panels was considered; (b) as ESS, a set of lithium batteries was considered; (c) as dc electrical appliances (dcEA), resistive loads were considered; (d) as ac electrical appliances (acEA), an induction motor was considered. In terms of the power converters: (a) for the ac-dc, full-bridge three-level converters were considered; (b) for the dc-dc, unidirectional and bidirectional half-bridge two-level converters were considered; (c) for the dc-ac, full-bridge three-level converters were considered. Based on the various opportunities of operation modes (cf. section 3 and Figure 7), the estimated efficiency was determined.

The efficiency was estimated for each case under study and considering all the possibilities of operation modes. The efficiency was measured in each power converter (ac-dc, $\mathrm{dc}-\mathrm{dc}$, and dc-ac) through computer simulations and real scenarios of operation considered in the model. By considering the dynamic models of the semiconductors (as provided by the manufacturer), it is possible to determine 
the conduction and switching losses. These operation modes are: (a) The power extracted from the RES can be injected into the power grid; (b) The power extracted from the RES can be used to charge the EV; (c) The power extracted from the RES can be used to charge the ESS; (d) The power extracted from the RES can be used by the electrical appliances; (e) The EV can deliver power for the smart home (electrical appliances); (f) The EV can deliver power for the smart grid; (g) The power from the ESS can be delivered to the smart home (electrical appliances); (h) The power from the ESS can be delivered to the smart grid; (i) The power from the grid can be used to charge the EV; (j) The power from the grid can be used to charge the ESS; (k) The power from the grid can be delivered to the smart home (electrical appliances).

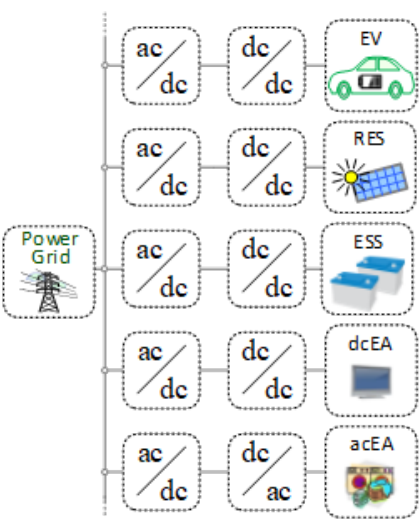

(a)

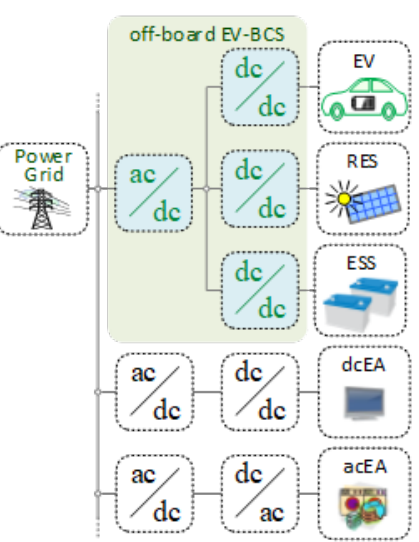

(b)

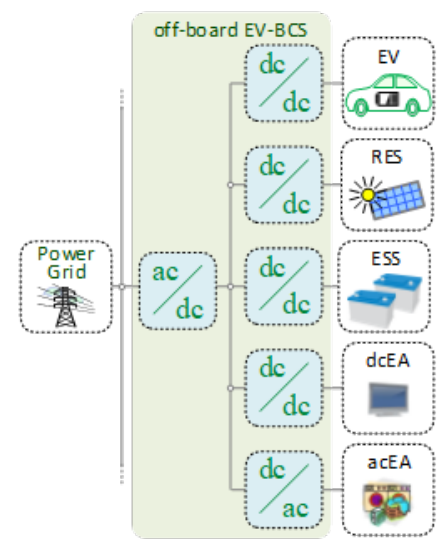

(c)

Figure 8. Cases under study: (a) A conventional ac smart home with independent power converters; (b) A hybrid ac and dc smart home; (c) A dc smart home.

The estimated efficiency, bearing in mind the three cases under study, is available in Figure 9 (for the case \#1, the ac-dc with an efficiency of $94 \%$, the dc-dc with an efficiency of $95 \%$, for the case \#2, the ac-dc with an efficiency of $95 \%$, and the dc-dc with an efficiency of $96 \%$, for the case \#3, the ac-dc with an efficiency of $95 \%$, and the dc-dc with an efficiency of $96 \%$ ). As it can be perceived, the most efficient case is attained with the dc smart home, where a single ac interface with the power grid is recognized. This follows the expectation, because the number of power stages is considerably diminished (as well as the needed amount of power converters). Taking into account that some operation modes are the same for some cases, comparable values of efficiency were achieved. On the other hand, the first case is the worst in terms of efficiency, since several power stages are needed, where the power grid is always needed for each operation mode.

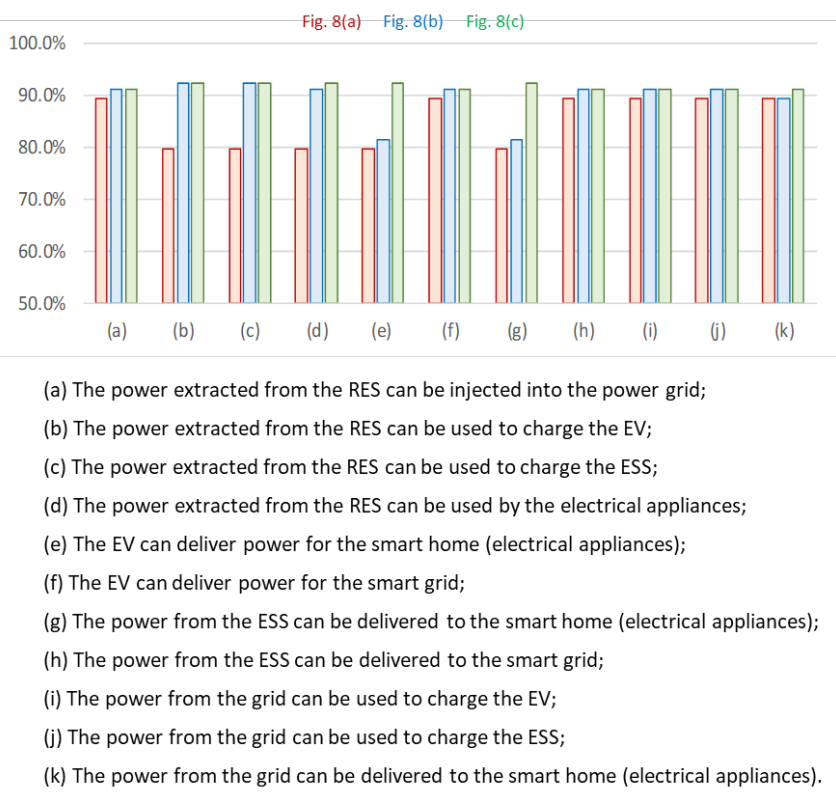

Figure 9. Estimated efficiency for each case under study and considering all the possibilities of operation modes.

Figure 10 shows the voltage $\left(v_{g}\right)$ and the current $\left(i_{g}\right)$ in the power grid when is injected power into the grid. This result was obtained considering the illustrated transient states, permitting to validate the dynamic operation of the control and the power topology. As highlighted, a matching aspect of the current in the PV panels $\left(i_{p v}\right)$, including its reference $\left(i_{p v}{ }^{*}\right)$ is also presented, clearly showing that the obtained signal is in harmony with the reference defined for this case, even with the dynamic operation. An operating power of $3.6 \mathrm{~kW}$ was considered in this case. As foreseen, the grid current $\left(i_{g}\right)$ is sinusoidal, and the converter operates with unitary power factor, independently of the variations due to the PV panels power production (which is worth highlighting as a great contribution to preserve high levels of power quality). The dc-dc converter used to interface the PV panels is controlled in order to extract, at each instant and based on a maximum power point tracking (MPPT) algorithm, the maximum power from the PV panels.

Figure 11 is presented a case when the EV is charged, both from the power grid and PV panels, showing the voltage $\left(v_{g}\right)$ and the current $\left(i_{g}\right)$, the current in the PV panels $\left(i_{p v}\right)$, and the current in the EV batteries $\left(i_{e v}\right)$. In this operation mode, the EV batteries are charged with constant current; therefore, as expected, the grid current varies in harmony with the current in the PV panels. As shown, the grid current does not present sudden variations, which is extremely relevant concerning power quality. 

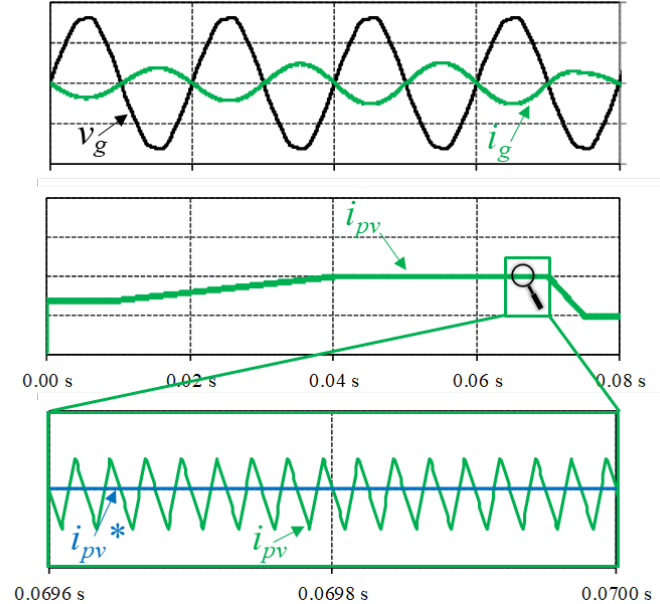

Figure 10. Simulation results when the power grid receives energy from the PV panels: Power grid voltage ( $v_{g}: 200 \mathrm{~V} /$ div); Grid current $\left(i_{g}: 30 \mathrm{~A} / \mathrm{div}\right)$; Current in the PV panels $\left(i_{p v}: 5 \mathrm{~A} / \mathrm{div}\right)$; Reference current for the PV panels $\left(i_{p v}{ }^{*}: 0.5 \mathrm{~A} / \mathrm{div}\right)$.
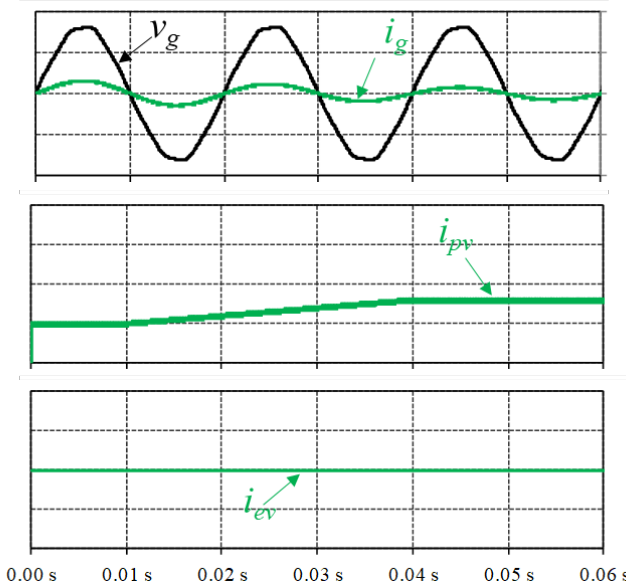

Figure 11. Simulation results when the EV batteries are charged with energy from the power grid and from the PV panels: Power grid voltage ( $v_{g}: 200 \mathrm{~V} /$ div); Grid current ( $i_{g}: 30 \mathrm{~A} /$ div); Current in the PV

panels ( $\left.i_{p v}: 10 \mathrm{~A} / \mathrm{div}\right)$; Current in the EV batteries $\left(i_{e v}: 10 \mathrm{~A} / \mathrm{div}\right)$.

A prototype was considered with the objective of introducing fundamental experimental results, validating some of the mentioned operations. Figure 12 shows the previous full-developed laboratory prototype, which was used in the scope of the original and this extended paper, to obtain the experimental validation. The prototype is internally organized by two main interrelated systems: power and control. Regarding the power system, it is constituted by three power electronics converters (where, for all of them, IGBT modules were considered due to their robustness for laboratorial validation purposes), namely an ac-dc power converter (with a full-bridge fully-controlled topology and bidirectional operation) to interface the power grid, a dc-dc power converter (with a boost-type topology and unidirectional operation) to interface the RES, and a dc-dc power converter (with a half-bridge topology and bidirectional operation) to interface the $\mathrm{EV}$, supporting the $\mathrm{G} 2 \mathrm{~V} / \mathrm{V} 2 \mathrm{G}$ modes. The three converters are linked through the same dc-link; however, they allow totally independent control from each other. On the other hand, the control system is constituted by the control IGBT drivers (in this case dedicated drivers for IGBT modules with double-channel), the signal conditioning board with an external bipolar ADC (i.e., avoiding to use the internal ADC, which only has unipolar channels), the current and voltage sensors for both ac and dc sides, and the F28335 DSP, which also provides a RS232 interface to interact with and receive actions for operation (i.e., by the user or by the smart home and smart grid, as presented along the paper).

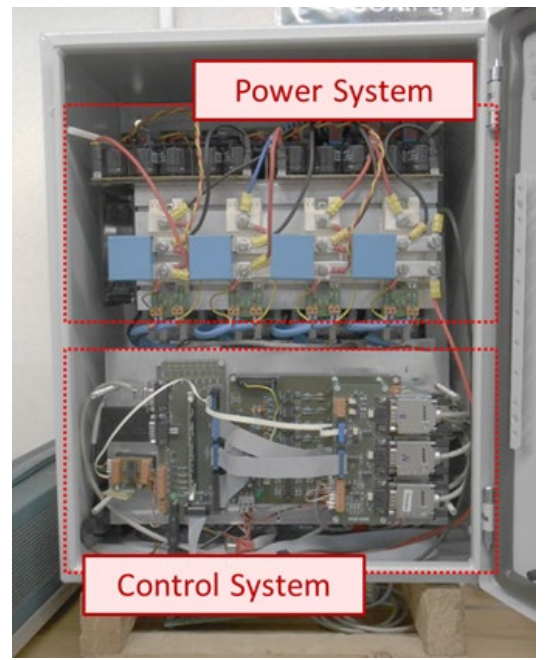

Figure 12. Laboratory prototype used to obtain the experimental validation.

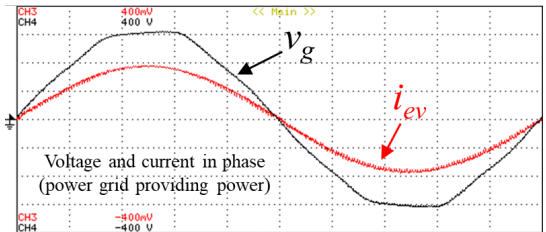

(a)

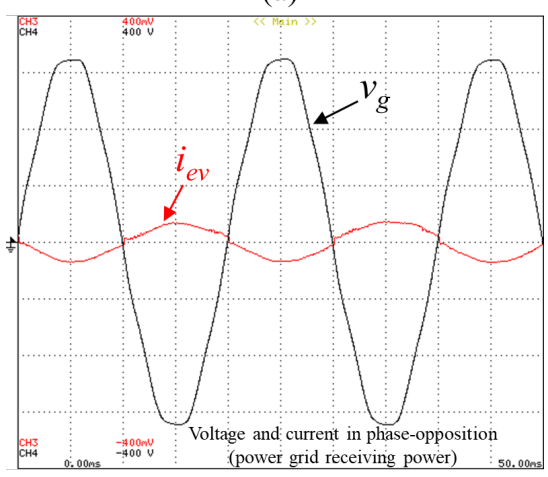

(b)

Figure 13. Experimental results when the EV batteries are charged (a) or discharged (b): Power grid voltage ( $\left.v_{g}: 100 \mathrm{~V} / \mathrm{div}\right)$; Grid current (ig: $10 \mathrm{~A} / \mathrm{div})$.

Figure 13(a) presents key experimental results regarding the EV charging from the power grid. As projected, to preserve power quality, the grid current $\left(i_{g}\right)$ is sinusoidal $(\mathrm{THD}=1.4 \%)$, even with a power grid voltage $\left(v_{g}\right)$ with harmonic distortion $(\mathrm{THD}=3.5 \%)$. With this strategy, the 
integrated topology does not contribute to the harmonic distortion of the power grid voltage, which is an essential characteristic. During the injection of power into the grid, Figure 13(b) shows, in a time interval of $50 \mathrm{~ms}$, the voltage $\left(v_{g}\right)$ and the current $\left(i_{g}\right)$ for an operating power of $800 \mathrm{~W}$. As expected, the current is in phase opposition with the voltage, meaning that the power grid receives energy from the PV panels.

In Figure 14 is presented an experimental result showing the current on the EV battery $\left(i_{b a t}\right)$ during the operation in G2V/V2G. This result is divided in five cases, where in cases 1,3 , and 5 the off-board EV-BCS is in idle mode. In case 2 , as well as in case 4 , the current increases slowly until to reach the steady state, aiming to prevent sudden variations, which can be harmful to both the off-board EV-BCS and batteries. It is important to note that this result was obtained on a small time scale $(100 \mathrm{~s})$, in order to present both modes $(\mathrm{G} 2 \mathrm{~V} / \mathrm{V} 2 \mathrm{G})$ and the respective transition. In Figure 15 is presented a case when the EV is charged from the power grid and PV panels, showing the power in the grid $\left(p_{g}\right)$, in the EV $\left(p_{e v}\right)$ and in the PV panels $\left(p_{p v}\right)$. As evidenced, $p_{g}$ is the difference between $p_{e v}$ and $p_{p v}$.

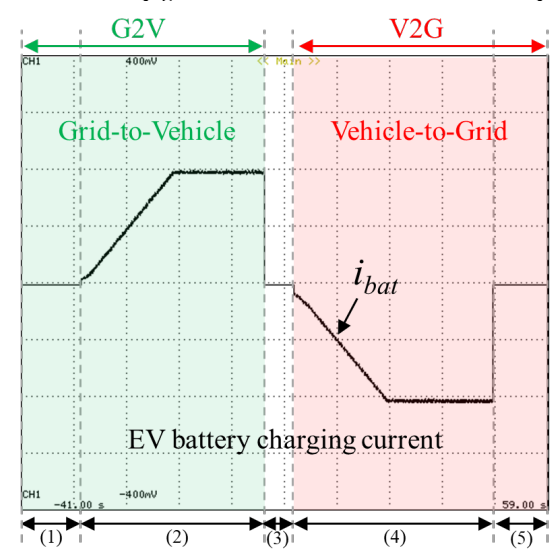

Figure 14. Experimental results when the EV batteries are charged $(\mathrm{G} 2 \mathrm{~V})$ or discharged (V2G): Current on the batteries (ibat: $5 \mathrm{~A} / \mathrm{div})$.

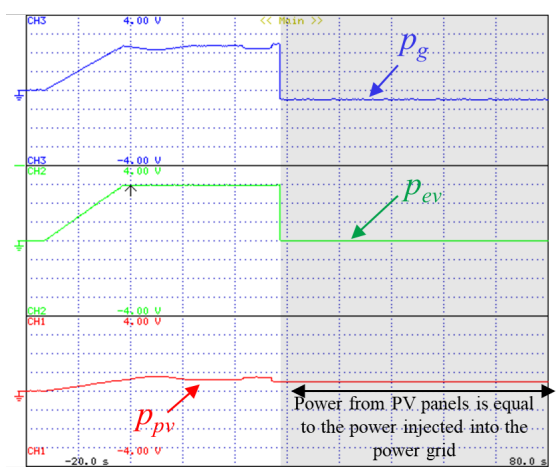

Figure 15. Experimental results when the EV batteries are charged with energy from the power grid and from the PV panels: Power in the grid $\left(p_{g}: 1 \mathrm{~kW} / \mathrm{div}\right)$; Power in the EV ( $\left.p_{\text {ev }}: 1 \mathrm{~kW} / \mathrm{div}\right)$; Power in the PV panels $\left(p_{p v}: 1 \mathrm{~kW} /\right.$ div $)$.

\section{Conclusions}

Around the world, innovative technologies are arising, in terms of hardware and software, for smart homes and smart grids, responding to needs raised by the electric mobility dissemination. Taking into account the electric vehicle (EV) pertinence in terms of operation modes for smart homes, the EV characterization is the main objective of this paper, where an assessment of the state of the art operation modes is utilized as a guideline to imminent new perspectives. Targeting to offer a broad study, on-board and off-board EV battery charging systems are considered and contextualized through scenarios of ac, dc and hybrid smart homes. Furthermore, the combination of ac and dc electrical appliances, energy storage systems and renewables is also contemplated from the point of view of smart homes.

The achieved results are based on three different situations (a conventional ac smart home with independent power converters, a hybrid ac and dc smart home, a dc smart home), focusing on the analysis in terms of energy efficiency. The results show that the first situation is the worst one, since all the technologies are connected to the power grid through an ac-dc power converter. Moreover, in such situation, for exchanging power among technologies (e.g., from renewable to the EV), the power grid is always required. A developed proof-of-concept prototype is described, and representative experimental results are shown. As possible restrictions can be identified on-board and the off-board EV chargers since the operation modes are dependent of the charger. For instance, the vehicle-for-grid mode is an exciting solution to mitigate power quality problems. From the point of view of off-board chargers, this mode can be considered independently of the EV since it is fixed and always connected to the power grid, which can be considered as an advantage. On the other hand, from the point of view of on-board chargers, there is the possibility to use the EV with the specified modes in the place where it is plugged-in, which can be identified as a restriction from the power grid point of view.

\section{Acknowledgment}

This work has been supported by FCT - Fundação para a Ciência e Tecnologia within the Project Scope: UID/CEC/00319/2019. This work has been supported by the FCT Project newERA4GRIDs PTDC/EEI-EEE/30283/2017, and by the FCT Project DAIPESEV PTDC/EEIEEE/30382/2017. Tiago Sousa is supported by the doctoral scholarship SFRH/BD/134353/2017 granted by FCT.

\section{References}

[1] Vítor Monteiro, José A. Afonso, João C. Ferreira, João L. Afonso, "Vehicle Electrification: New Challenges and Opportunities for Smart Grids," MDPI Energies, vol.12, no.1, pp.1-20, Dec. 2018.

[2] Wencong Su, Habiballah Rahimi-Eichi, Wente Zeng, MoYuen Chow, "A Survey on the Electrification of 
Transportation in a Smart Grid Environment," IEEE Trans. Ind. Electron., vol.8, no.1, pp.1-10, Feb. 2012.

[3] Rafael Leite, João L. Afonso, Vítor Monteiro, "A Novel Multilevel Bidirectional Topology for On-Board EV Battery Chargers in Smart Grids", MDPI Energies, vol.11, no.12, pp.1-21, Dec. 2018.

[4] Vítor Monteiro, João C. Ferreira, Andrés A. Nogueiras Meléndez, João L. Afonso, "Model Predictive Control Applied to an Improved Five-Level Bidirectional Converter", IEEE Transactions on Industrial Electronics, vol.63, no.9, pp.5879-5890, Sept. 2016

[5] Vítor Monteiro, João C. Ferreira, Andrés A. Nogueiras Meléndez, Carlos Couto, João L. Afonso, Experimental Validation of a Novel Architecture Based on a Dual-Stage Converter for Off-Board Fast Battery Chargers of Electric Vehicles, IEEE Trans. Veh. Technol., vol.67, no.2, pp.10001011, Feb. 2018.

[6] Vítor Monteiro, Tiago J. C. Sousa, Rafael Leite, J. C. Aparício Fernandes, Carlos Couto, João L. Afonso, "Comprehensive Analysis and Experimental Validation of Five-Level Converters for EV Battery Chargers Framed in Smart Grids," YEF-ECE International Young Engineers Forum on Electrical and Computer Engineering, Almada Portugal, May 2019.

[7] Deepak S. Gautam, Fariborz Musavi, Murray Edington, Wilson Eberle, William G. Dunford, "An Automotive Onboard 3.3-kW Battery Charger for PHEV Application," IEEE Trans. Veh. Technol., vol.61, no.8, pp.3466-3474, Oct. 2012.

[8] C. C. Chan, Alain Bouscayrol, Keyu Chen, "Electric, Hybrid, and Fuel-Cell Vehicles: Architectures and Modeling," IEEE Trans. Veh. Technol., vol.59, no.2, pp.589-598, Feb. 2010.

[9] João C. Ferreira, Vitor Monteiro, João L. Afonso, "Vehicleto-Anything Application (V2Anything App) for Electric Vehicles," IEEE Trans. Ind. Informat., vol.10, no.3, pp.19271937, Aug. 2014.

[10] Vítor Monteiro, Bruno Exposto, João C. Ferreira, João L. Afonso, "Improved Vehicle-to-Home (iV2H) Operation Mode: Experimental Analysis of the Electric Vehicle as OffLine UPS," IEEE Transactions on Smart Grid, vol.8, no.6, pp.2702-2711, Nov. 2017.

[11] Marc Multin, Florian Allerding, Hartmut Schmeck, "Integration of Electric Vehicles in Smart Homes - An ICTbased Solution for V2G Scenarios," IEEE ISGT PES Innovative Smart Grid Technologies, pp.1-8, Jan. 2012.

[12] Yutaka Ota, Haruhito Taniguchi, Tatsuhito Nakajima, Kithsiri M. Liyanage, Jumpei Baba, Akihiko Yokoyama, "Autonomous Distributed V2G (Vehicle-to-Grid) Satisfying Scheduled Charging," IEEE Trans. Smart Grids, vol.3, no.1, pp.559-564, Mar. 2012.

[13] Murat Yilmaz, Philip T. Krein, "Review of the Impact of Vehicle-to-Grid Technologies on Distribution Systems and Utility Interfaces," IEEE Trans. Power Electron., vol.28, no.12, pp.5673-5689, Dec. 2013.

[14] Rong Yu, Weifeng Zhong, Shengli Xie, Chau Yuen, Stein Gjessing, Yan Zhang, "Balancing Power Demand through EV Mobility in Vehicle-to-Grid Mobile Energy Networks," IEEE Trans. Ind. Informat., vol.12, no.1, pp.79-90, Feb. 2016.

[15] N. Chen, M. Wang, N. Zhang, X. Shen, "Energy and Information Management of Electric Vehicular Network: A
Survey," IEEE Communications Surveys \& Tutorials, vol.22, no.2, pp.967-997, Secondquarter 2020.

[16] Vítor Monteiro, J. G. Pinto, João L. Afonso, "Operation Modes for the Electric Vehicle in Smart Grids and Smart Homes: Present and Proposed Modes," IEEE Trans. Veh. Tech., vol.65, no.3, pp.1007-1020, Mar. 2016.

[17] Vítor Monteiro, José A. Afonso, Joao C. Ferreira, Tiago J. C. Sousa, Joao L. Afonso, "The Electric Vehicle in Smart Homes: A Review and Future Perspectives," EAI SESC International Conference on Sustainable Energy for Smart Cities, Braga, Portugal, Dec. 2019.

[18] B. Mroczek, A. Kołodyńska, "The V2G Process With the Predictive Model," IEEE Access, vol.8, pp.86947-86956, 2020.

[19] João A. Peças Lopes, Filipe Soares, Pedro M. Rocha Almeida, "Integration of Electric Vehicles in the Electric Power Systems," Proc. IEEE, vol.99, no.1, pp.168-183, Jan. 2011.

[20] Peter Richardson, Damian Flynn, Andrew Keane, "Optimal Charging of Electric Vehicles in Low-Voltage Distribution Systems," IEEE Trans. Power Syst., vol.27, no.1, pp.268-279, Feb. 2012.

[21] Rong-Ceng Leou, "Optimal Charging/Discharging Control for Electric Vehicles Considering Power System Constraints and Operation Costs," IEEE Trans. Power Syst., vol.31, no.3, pp.1854-1860, May 2016.

[22] João C. Ferreira, Vitor Monteiro, João L. Afonso, "Electric Vehicle Assistant Based on Driver Profile," Int. J. Electric and Hybrid Vehicles, vol.6, no.4, pp.335-349, 2014.

[23] Vítor Monteiro, Andrés A. Nogueiras Meléndez, Carlos Couto, João L. Afonso, "Model Predictive Current Control of a Proposed Single-Switch Three-Level Active Rectifier Applied to EV Battery Chargers," IEEE IECON Industrial Electronics Conference, Florence Italy, pp.1365-1370, Oct. 2016.

[24] An Luo, Qianming Xu, Fujun Ma, Yandong Chen, "Overview of Power Quality Analysis and Control Technology for the Smart Grid," SPRINGER Journal of Modern Power Systems and Clean Energy, vol.4, no.1, pp.19, Jan. 2016.

[25] Mingrui Zhang, Jie Chen, "The Energy Management and Optimized Operation of Electric Vehicles Based on Microgrid," IEEE Trans. Power Del., vol.29, no.3, pp.14271435, June 2014.

[26] C. Gouveia, D. Rua, F. Ribeiro, L. Miranda, J. M. Rodrigues, C. L. Moreira, J. A. Peças Lopes, "Experimental Validation of Smart Distribution Grids: Development of a Microgrid and Electric Mobility Laboratory," ELSEVIER Electrical Power and Energy Systems, vol.78, pp.765-775, June 2016.

[27] Matthias D. Galus, Marina Gonzalez Vaya, Thilo Krause, Goran Andersson, "The Role of Electric Vehicles in Smart Grids," John Wiley and Sons, WIREs Energy Environ, vol.2, pp.384-400, Aug. 2013.

[28] Vítor Monteiro, João C. Ferreira, João L. Afonso, “Operation Modes of Battery Chargers for Electric Vehicles in the Future Smart Grids," in Technological Innovation for Collective Awareness Systems, 1st ed., Luis M. Camarinha-Matos, Luis M. Barreto, Nuno S. Mendonça, Ed. Springer, 2014, Chapter 44, pp.401-408.

[29] Vítor Monteiro, João C. Ferreira, Andrés A. Nogueiras Meléndez, João L. Afonso, "Electric Vehicles On-Board Battery Charger for the Future Smart Grids," in Technological Innovation for the Internet of Things, 1st ed., 
Luis M. Camarinha-Matos, Slavisa Tomic, Paula Graça, Ed. Springer, 2013, Chapter 38, pp.351-358.

[30] David P. Tuttle, Ross Baldick, "The Evolution of Plug-In Electric Vehicle-Grid Interactions," IEEE Trans. Smart Grid, vol.3, no.1, pp.500-505, Mar. 2012.

[31] X. Chen, K. Leung, A. Y. S. Lam, D. J. Hill, "Online Scheduling for Hierarchical Vehicle-to-Grid System: Design, Formulation, and Algorithm," IEEE Trans. Veh. Technol. vol.68, no.2, pp.1302-1317, Feb. 2019.

[32] C. Schuss, T. Fabritius, B. Eichberger, T. Rahkonen, "Impacts on the Output Power of Photovoltaics on Top of Electric and Hybrid Electric Vehicles," IEEE Trans. Instrumentation and Measurement, vol.69, no.5, pp.2449-2458, May 2020.

[33] Jorge E. Hernandez, Frank Kreikebaum, Deepak Divan, "Flexible Electric Vehicle (EV) Charging to Meet Renewable Portfolio Standard (RPS) Mandates and Minimize Green House Gas Emissions," IEEE ECCE Energy Conversion Congress and Exposition, Atlanta USA, pp.4270-4277, Sept. 2010 .

[34] Ahmed Yousuf Saber, Ganesh Kumar Venayagamoorthy, "Plug-in Vehicles and Renewable Energy Sources for Cost and Emission Reductions,'IEEE Trans. Ind. Electron., vol.58, no.4, pp.1229-1238, Apr. 2011.

[35] Mosaddek Hossain Kamal Tushar, AdelW. Zeineddine, Chadi Assi, "Demand-Side Management by Regulating Charging and Discharging of the EV, ESS, and Utilizing Renewable Energy," IEEE Trans. Ind. Informat., vol.14, no.1, pp.117126, Jan. 2018

[36] Vehbi C. Gungor, Dilan Sahin, Taskin Kocak, Salih Ergut, Concettina Buccella, Carlo Cecati, Gerhard P. Hancke, "Smart Grid and Smart Homes - Key Players and Pilot Projects," IEEE Ind. Electron. Mag., vol.6, pp.18-34, Dec. 2012.

[37] Chunhua Liu, K. T. Chau, Diyun Wu, Shuang Gao, "Opportunities and Challenges of Vehicle-to-Home, Vehicleto-Vehicle, and Vehicle-to-Grid Technologies," Proc. IEEE, vol.101, no.11, pp.2409-2427, Nov. 2013.

[38] Chenrui Jin, Jian Tang, Prasanta Ghosh, “Optimizing Electric Vehicle Charging: A Customer's Perspective," IEEE Trans. Veh. Technol., vol.62, no.7, pp.2919-2927, Sept. 2013.

[39] Vítor Monteiro, J. G. Pinto, João L. Afonso, "Improved Vehicle-for-Grid (iV4G) Mode: Novel Operation Mode for EVs Battery Chargers in Smart Grids," ELSEVIER International Journal of Electrical Power and Energy Systems, vol.110, pp.579-587, Mar. 2019.

[40] Vítor Monteiro, Tiago J. C. Sousa, M. J. Sepúlveda, Carlos Couto, António Lima, João L. Afonso, "A Proposed Bidirectional Three Level dc dc Power Converter for Applications in Smart Grids: An Experimental Validation”, IEEE SEST International Conference on Smart Energy Systems and Technologies, Porto, Portugal, Sept. 2019.

[41] X. Hou, J. Wang, T. Huang, T. Wang, P. Wang, "Smart Home Energy Management Optimization Method Considering Energy Storage and Electric Vehicle," IEEE Access, vol.7, pp.144010-144020, 2019.

[42] H. Kikusato et al., "Electric Vehicle Charge-Discharge Management for Utilization of Photovoltaic by Coordination Between Home and Grid Energy Management Systems," IEEE Trans. Smart Grid, vol.10, no.3, pp.3186-3197, May 2019
[43] M. Shin, D. Choi, J. Kim, "Cooperative Management for PV/ESS-Enabled Electric Vehicle Charging Stations: A Multiagent Deep Reinforcement Learning Approach," IEEE Trans. Ind. Informat., vol.16, no.5, pp.3493-3503, May 2020.

[44] Vítor Monteiro, J. G. Pinto, João L. Afonso, "Experimental Validation of a Three-Port Integrated Topology to Interface Electric Vehicles and Renewables with the Electrical Grid", IEEE Transactions on Industrial Informatics, vol.14, no.6, pp 2364-2374, June 2018.

[45] Vítor Monteiro, Tiago J. C. Sousa, Carlos Couto, Júlio S. Martins, Andres A. Nogueiras Melendez, João L. Afonso, “A Novel Multi-Objective Off-Board EV Charging Station for Smart Homes", IEEE IECON Industrial Electronics Conference, pp.1893-1988, Washington D.C., United States of America, Oct. 2018 